\title{
CONTENT AND (ENGLISH) LANGUAGE INTEGRATED LEARNING (CLIL) APPLIED TO MATH LESSONS
}

\author{
Azamat Akbarov, Kemal Gönen, Hakan Aydoğan
}

\begin{abstract}
The main purpose of this article was to examine students' experiences, opinions, perceptions, attitudes, and preferences with regard to math classes where content and language integrated learning (CLIL) approach was applied. A total of 125 students from the Kazakh National University participanted in the present study. Their mean age was $\mathrm{M}=18.12(\mathrm{SD}=0.96)$. There were $73(58.4 \%)$ females and $52(41.6 \%)$ males in the sample. The questionnaire administered to our participants was created to include questions relevant to this study. Results indicated that participants had moderate attitudes, preferences, and satisfaction with regard to CLIL approach wherein English was used as a medium in the delivery of math contents. Students' English competences were somehow improved and their attitudes toward British and American culture became more positive. Participants' level of English proficiency was in positive and significant correlations with their preferences of math classes and other subjects taught in English. Some shortcomings of the present study and recommendations for further studies of this topic were enclosed as well.
\end{abstract}

Key words: Content and language integrated learning (CLIL), English as a foreign language (EFL), math classes

\section{Introduction}

CLIL stands for "content and language integrated learning" and is defined as learning both language and contents of a particular school subject or academic course. This language is not students' mother tongue (Marsh, 2002). It is often the second (L2) or a foreign language such as English (Favilli, Maffei, \& Peroni, 2013). Nowadays, CLIL environments are very common due to global nature of English, the language which serves as a medium through which subject matter contents are delivered to students and learned by them (King, 2018). In addition, CLIL model helps students raise their levels of second/foreign language proficiency (Lasagabaster \& Sierra, 2010). This can be regarded as an adjustment of the traditional approach to teaching/learning a language (Bobadilla-Perez \& GalanRodriguez, 2015). Thus, content and language integrated learning has a dual aim - learning the content of a school subject and learning language used to teach this content (Coyle, Hood, \& Marsh, 2010).

Coyle $(1999,2005,2007)$ proposed the following four principles or segments of CLIL (so-called 4Cs): 1) content (What is the topic within a particular school subject or academic course?), cognition (What are the mental processes involved in acquiring a particular lesson?), communication (What language are learners and teachers using while talking about specific concepts within that lesson?), and culture/community (What is the (multi)cultural aspect of the lesson that currently taught?).

The possible benefits of CLIL can be summarized as follows: it increases intercultural awareness (or sensitivity), CLIL improves motivation in students, it is useful for learners with different levels of ability, and CLIL produces a higher level of achievements in the foreign language used in the process of teaching and learning (Harrop, 2012). Students involved in CLIL classrooms had higher levels of intrinsic motivation compared to those who were in regular EFL (English as a foreign classroom) classrooms (Lasagabaster \& Beloqui, 2015). CLIL-exposed students reported a higher level of English skills as well as a greater degree of understanding of concepts taught within school subjects (De Lama, 2015). 
A study carried out into students' attitudes toward CLIL in science revealed that most of them were satisfied with instruction delivered in English, classes in English were more interesting compared to those in mother tongue, there was more cooperation between students and teachers when contents were taught in English, and students made more additional effort because of English-mediated teaching and learning (Papaja, 2012). In the same study, students' did not report more positive attitudes toward British and American culture, as a result of CLIL-based instruction. When CLIL applied to math classes, students estimated these teaching methods as good, different, fun, and new compared to traditional teaching in their native language (Prochazkova, 2013).

The aim of this study was to investigate students' perceptions, attitudes, opinions, and satisfaction with regard to using English as a language of instruction in math classes. The following research questions emerged from the main aim of the present study:

1. What is the level of students' satisfaction with math contents taught in English and how much do they like such CLIL-based classes?

2. What amount of effort do students put into preparing exams and doing their homework for English-taught math classes, along with participation in such classes?

3. To what extent did CLIL-based math classes improve students' English knowledge and skills along with their attitudes toward British and American culture?

4. How much do students like English-taught classes, compared to those taught in their mother tongue?

5. Does English proficiency level correlate with the preferences/satisfaction with CLIL-based math classes and preferences of CLIL-based classes in general?

6. Do preferences and satisfaction with CLIL-based math classes and difficulties with acquiring math concepts in English correlate with students' grades on the last math exam?

\section{Methodology}

\subsection{Sample}

We recruited 125 students from Kazakh National University. There were more females $(N=73$ or $58.4 \%$ of the whole sample) than males $(N=52$, i.e. $41.6 \%)$ in our sample. Participants' mean age was $M=18.12$ while standard deviation was calculated as $S D=0.96$ years of age. The age range was 17 to 21 years.

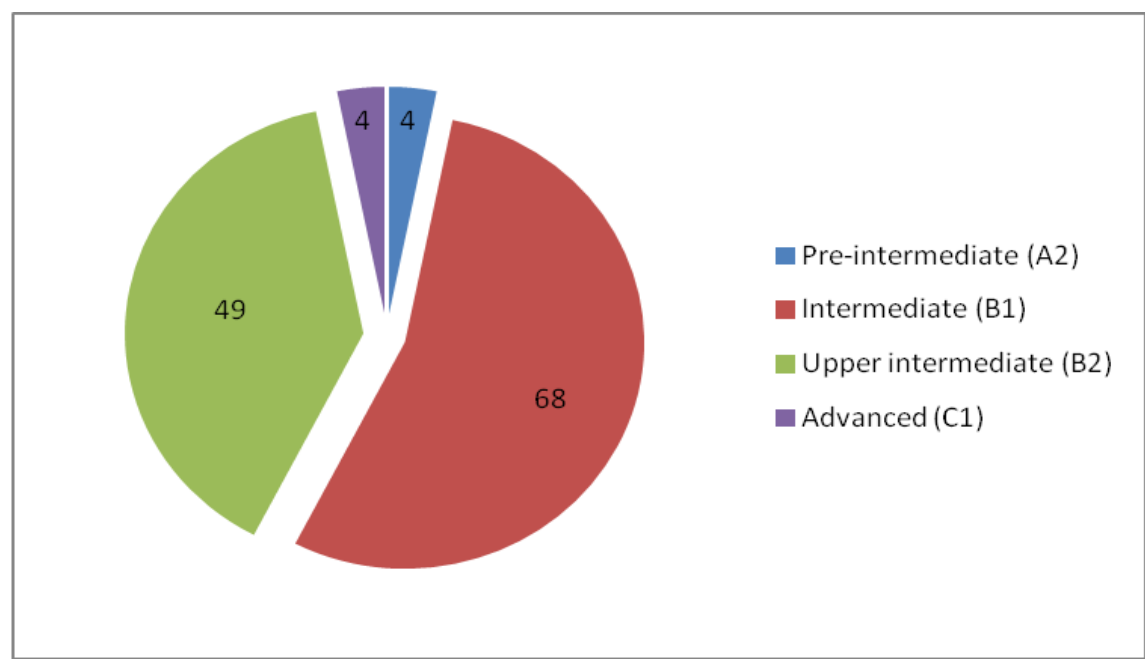

Figure 1. Number of participants by their level of English proficiency

Participants were divided into four groups, based on their level of English proficiency (Figure 1): preintermediate level - A2 (four participants, which is $3.2 \%$ of the total sample), intermediate level - B1 $(N=68$, i.e. $54.4 \%$ of the total sample), upper-intermediate level $-\mathrm{B} 2(N=49$, or $39.2 \%)$, and 
advanced level $-\mathrm{C} 1(N=4$, i.e. $3.2 \%$ of the whole sample). Additionally, none of them reported either elementary (A1) or proficient (C2) level of English knowledge and skills (competencies).

We also asked students to provide the number of years they have been learning English. The mean of their answers was $M=5.54$ years with standard deviation of $S D=3.17$. The smallest number of reported years was one whereas the greatest one was 15 .

\subsection{Instruments}

A questionnaire was created in order to encompass some sociodemographics/general questions (participants' age, gender, grades at last math exam, number of years spent in learning English, and English proficiency level) as well as some key elements of CLIL (participants' effort they put into CLIL-based math lessons, exams, and assignments; their satisfaction with such classes and attitudes toward them, benefits from CLIL environment, preferences of CLIL and traditional math classroom, and attitudes toward British and American culture influenced by CLIL-based math course). The full questionnaire (with 15 questions) was enclosed under the title Appendix.

\subsection{Research Procedure and Data Processing}

The questionnaire was administered to students who agreed to voluntarily participate in this study. Their anonymity and confidentiality of their answers were guaranteed by the researcher. In addition, the author of this study told participants that their answers on the questionnaire will in no way impact their math grades.

Data were analyzed by the means of descriptive (frequencies, percentages, arithmetic means, standard deviation, minimum and maximum values) and inferential (chi-square test and correlation) procedures. All of them were conducted in SPSS for Windows (ver. 23.0).

\section{Results}

Results were given in the order of the research questions from the introductory part of this article. The level of students' satisfaction with math classes taught in English was shown in Table 1, whereas their preferences of this kind of classes were displayed in Table 2. These data referred to the first research question.

Table 1. Students' satisfaction with English-taught math classes

\begin{tabular}{|c|c|c|c|c|c|c|}
\hline Level of satisfaction with English-taught math classes & $\mathrm{f}$ & $\%$ & Min & Max & $\mathrm{M}$ & SD \\
\hline Very low level of satisfacion & 21 & 16.8 & \multirow{5}{*}{1} & \multirow{5}{*}{5} & \multirow{5}{*}{2.89} & \multirow{5}{*}{1.23} \\
\hline Low level of satisfaction & 23 & 18.4 & & & & \\
\hline Moderate level of satisfaction & 45 & 36.0 & & & & \\
\hline High level of satisfaction & 21 & 16.8 & & & & \\
\hline Very high level of satisfaction & 15 & 12.0 & & & & \\
\hline
\end{tabular}

As can be noticed in Table 1, students' were moderately satisfied with English-taught math classes, i.e. with CLIL-based math lessons. This was the case because the largest number of them $(f=45$, or $36 \%$ of the total sample) chose the middle answering option. Additionally, the mean of their answers was $M=2.89$ (this, close to the theoretical mean, which equals to 3 ).

As a supplementary result to the previous one, we noticed that students' preferences, expressed numerically, were slightly below the theoretical average of the five-point scale used in this case too $(M$ $=2.81$ which is less than 3 , see Table 2). 
Table 2. Students' preferences of math classes taught in English

\begin{tabular}{|c|c|c|c|c|c|c|}
\hline Preferences of English-taught math classes & $\mathrm{f}$ & $\%$ & Min & Max & $\mathrm{M}$ & SD \\
\hline Totally dislike them & 33 & 26.4 & \multirow{5}{*}{1} & \multirow{5}{*}{5} & \multirow{5}{*}{2.81} & \multirow{5}{*}{1.42} \\
\hline Dislike them & 19 & 15.2 & & & & \\
\hline Neither like nor dislike & 33 & 26.4 & & & & \\
\hline Like them & 19 & 15.2 & & & & \\
\hline Like them very much & 21 & 16.8 & & & & \\
\hline
\end{tabular}

The same number of participants $(N=33$, i.e. $26.4 \%)$ chose the two options - totally dislike and neither like nor dislike English-taught math courses.

To answer the second research question, we referred to Table 3, 4, and 5 below.

Table 3. The amount of students' effort they put into preparing for the exams of CLIL-based math classes

\begin{tabular}{|c|c|c|c|c|c|c|}
\hline The amount of effort (exams) & $\mathrm{f}$ & $\%$ & Min & Max & $\mathrm{M}$ & SD \\
\hline Very little & 20 & 16.0 & \multirow{5}{*}{1} & \multirow{5}{*}{5} & \multirow{5}{*}{3.10} & \multirow{5}{*}{1.30} \\
\hline Small & 18 & 14.4 & & & & \\
\hline Moderate/average & 39 & 31.2 & & & & \\
\hline Great & 26 & 20.8 & & & & \\
\hline Very great & 22 & 17.6 & & & & \\
\hline
\end{tabular}

On average, participants' reported moderate or average amount of effort they put into activities for the preparation of CLIL-based math exams $(f=39$, that is, $31.2 \%$ of the total sample, $M=3.10$, see Table $3)$.

Table 4. The amount of students' effort they put into doing homework for CLIL-based math classes

\begin{tabular}{|l|c|c|c|c|c|c|}
\hline The amount of effort (homework) & $\mathrm{f}$ & $\%$ & Min & Max & M & SD \\
\hline Very little & 22 & 17.6 & & & & \\
Small & 14 & 11.2 & & & \\
Moderate/average & 39 & 31.2 & \multirow{2}{*}{1} & 5 & \multirow{3}{*}{3.06} & 1.26 \\
\hline Great & 35 & 28.0 & & & & \\
\hline Very great & 15 & 12.0 & & & & \\
\hline
\end{tabular}

Similarly, most of our participants reported a moderate amount of effort in relation to doing homework within CLIL-based math classes $(f=39$, i.e. $31.2 \%$, see Table 4$)$. The mean value of their estimates was $M=3.06$ (thus, its value was somewhat above the theoretical average).

Table 5. The amount of students' effort they put into participation in CLIL-based math classes

\begin{tabular}{|l|c|c|c|c|c|c|}
\hline The amount of effort (participation) & f & $\%$ & Min & Max & M & SD \\
\hline Very little & 25 & 20.0 & & & & \\
Small & 15 & 12.0 & & & \\
Moderate/average & 45 & 36.0 & \multirow{2}{*}{1} & 5 & \multirow{2}{*}{2.92} & 1.27 \\
\hline Great & 25 & 20.0 & & & & \\
\hline Very great & 15 & 12.0 & & & & \\
\hline
\end{tabular}

Most students also assessed they put a moderate amount of effort into participation in English-taught math classes $(f=45$, that is, $36 \%$ of the whole sample). Additionally, the arithmetic mean of their estimates was slightly below the theoretical average $(M=2.92$, see Table 5).

Tables 6 and 7 were related to the third research question. They displayed figures in relation to possible benefits from CLIL approach used during math lessons. Most participants reported their English skills and knowledge had been moderately improved by participating in CLIL-based math classes. 
Table 6. The extent to which students' English competencies have been improved due to CLIL-based math classes

\begin{tabular}{|c|c|c|c|c|c|c|}
\hline Extent to which Englsh competences have been improved: & $\mathrm{f}$ & $\%$ & Min & $\operatorname{Max}$ & $\mathrm{M}$ & SD \\
\hline Very small & 14 & 11.2 & \multirow{5}{*}{1} & \multirow{5}{*}{5} & \multirow{5}{*}{3.11} & \multirow{5}{*}{1.16} \\
\hline Small & 20 & 16.0 & & & & \\
\hline Moderate & 44 & 35.2 & & & & \\
\hline Great & 32 & 25.6 & & & & \\
\hline Very great & 15 & 12.0 & & & & \\
\hline
\end{tabular}

More precisely, 44 of them, which is $35.2 \%$ of the total sample (see Table 6). Accordingly, the mean value of their answers was $M=3.11$, thus, above the average.

Table 7. The way English-taught math classes changed students' attitudes toward British and American culture

\begin{tabular}{|c|c|c|c|c|c|c|}
\hline Attitudes toward British and American culture became: & $\mathrm{f}$ & $\%$ & Min & Max & $\mathrm{M}$ & SD \\
\hline Very negative & 2 & 1.6 & \multirow{5}{*}{1} & \multirow{5}{*}{5} & \multirow{5}{*}{3.84} & \multirow{5}{*}{1.04} \\
\hline Negative & 9 & 7.2 & & & & \\
\hline Neutral & 40 & 32.0 & & & & \\
\hline Positive & 30 & 24.0 & & & & \\
\hline Very positive & 44 & 35.2 & & & & \\
\hline
\end{tabular}

The largest portion of our sample reported very positive attitudes toward British and American culture, as a result of English-taught math classes ( $f=44$, i.e. $35.2 \%$ of the whole sample, see Table 7). Moreover, the mean value of their estimates was significantly above the theoretical average $(M=$ 3.84).

Table 8. Students' preferences of learning subject contents in English, their mother tongue, and in both ways

\begin{tabular}{|c|c|c|c|c|c|}
\hline $\begin{array}{l}\text { Students' preferences of learning subject } \\
\text { contents in the three following ways: }\end{array}$ & $\mathrm{f}$ & $\%$ & $\chi^{2}$ & df & $\mathrm{p}$ \\
\hline Like to learn them in English & 50 & 40.0 & \multirow{3}{*}{2.800} & \multirow{3}{*}{2} & \multirow{3}{*}{.247} \\
\hline Like to learn them in their mother tongue & 40 & 32.0 & & & \\
\hline Equally like both options & 35 & 28.0 & & & \\
\hline
\end{tabular}

As shown in Table 8, most students liked to learn subject contents in English ( $f=50$, i.e. $40 \%)$. Next, 40 of them (that is, $32 \%$ ) liked to learn this kind of contents in their mother tongue. Finally, 35 students ( $28 \%$ of the total sample) reported they equally like both options of learning subject contents. However, the difference between these frequencies (i.e. the number of participants who chose each of the mentioned answering options) was not statistically significant $\left(\chi^{2}=2.800, d f=2, p>.05\right)$. This was the answer to the fourth research question.

Table 9. The relationships of students' English level proficiency with their preferences/satisfaction with CLILbased math and other classess

\begin{tabular}{|l|c|c|}
\hline \multirow{2}{*}{ Level of satisfaction with English-taught math classes } & \multicolumn{2}{|c|}{ English proficiency level } \\
\cline { 2 - 3 } & $\mathrm{r}$ & $\mathrm{p}$ \\
\hline Preferences of English-taught math classes & .232 & .009 \\
\hline Preferences of learning subject contents in English & .153 & .088 \\
\hline
\end{tabular}

Table 9 displayed correlations necessary for answering the penultimate research question. As could be noticed, students' level of English proficiency was in a small, positive, and statistically significant relationships with level of satisfaction with English-taught math classes $(r=.232, p<.01)$ and preferences if learning subject contents (in general) in English $(r=.227, p<.05)$. The statistical significance of the correlation between students' English proficiency levels and their preferences of English-taught math classes was relatively close to the cutoff value of $.05(r=.153, p=.088)$. 
Table 10. The correlation of students' math grades with their preferences/satisfaction with CLIL-based math lessons and difficulties encountered this kind of classes

\begin{tabular}{|l|c|c|}
\hline \multirow{2}{*}{} & \multicolumn{2}{|c|}{ Math grades (marks) } \\
\cline { 2 - 3 } & $\mathrm{r}$ & $\mathrm{p}$ \\
\hline Level of satisfaction with English-taught math classes & .127 & .160 \\
\hline Preferences of English-taught math classes & .045 & .617 \\
\hline $\begin{array}{l}\text { Difficulties with understanding math concepts while learning } \\
\text { them in English }\end{array}$ & -.127 & .157 \\
\hline
\end{tabular}

Looking at Table 10, we realized that none of the correlation coefficients was statistically significant (all $p_{\mathrm{s}}>.05$ ). Hence, students' grades on their last math exam were neither in statistically significant correlations with their satisfaction/preferences of English-taught math classes nor with difficulties encountered while learning math concepts in English. This was the answer to our last research question.

\section{Discussion}

This research dealt with students' opinions, attitudes, preferences, and perceptions regarding content and (English) language integrated learning applied to teaching and learning framework of math as a school subject or academic course.

In general, students' levels of satisfaction and their preferences of English-taught math classes were the range of average values. Papaja (2012) reported that participants in his study were pretty satisfied with math classes taught in English. The reason for some discrepancy between his and our findings can be a result of cultural (Asian vs Latin American) difficulties. A moderate degree of satisfaction/ preference was obtained in the study conducted by Prochazkova (2013), which was in accordance with this portion of our results.

Next, students reported making a moderate effort while participating in math classes taught in English, preparing for the exams, and doing their assignments. Generally speaking, math is a difficult subject/course. Hence, their efforts were not as high as somebody would expect based on the combination of a difficult subject and the usage of foreign language (i.e. English).

According to our participants, CLIL-based math lessons improved their English knowledge and skills. This finding was comparable with that of Harrop (2012) as well as Lasagabaster and Sierra (2010). Students' attitudes toward British and American culture improved also, unlike those of the students involved in the research carried out by Papaja (2012). However, it was similar to the finding obtained in the cited study of Harrop (2012).

Participants in the present study liked math classes taught in English and their mother tongue (predominantly Kazakh or Russian) almost equally. There was also a large number of those who liked both options (teaching subject contents in English or mother tongue).

As expected, participants' level of English proficiency was in a positive correlation with their satisfaction with math classes taught in English. However, this correlation was small (but statistically significant!), as was the relationship between English proficiency levels and students' preferences of learning subject contents in English (which was also statistically significant).

In contrast, math grades (marks) were not significantly influenced by students' level of satisfaction with CLIL-based math classes, their preference, and difficulties with understanding math concepts delivered and explained in English. This was probably due to the complexity of this subject matter, learning habits, motivation, numerical intelligence, and some other factors that have a greater impact on academic performance/achievements.

There were some disadvantages of this study that can be overcome in future research within the same area. These were, in the first place, the following: self-report measures can and usually are biased because of the subjectivity factor, math grades at the last exam are only a sample of students' grades (thus, students' performance at other math exams should be included as well), and participants' attitudes and preferences regarding non-CLIL-based (classic, traditional) math classes should be 
compared with their attitudes and preferences of CLIL-based classes (that is, we analyzed their experiences with CLIL-based math classes only). Therefore, these shortcomings included recommendations for further studies of CLIL-based math and other classes. We can add that teachers' opinions, perceptions, and preferences with regard to the same topic matter as well.

\section{Conclusion}

As highlighted before, students' from our sample had moderate attitudes toward CLIL approach in math lessons. Their preferences, estimates, and other opinions were similar (with the exception of attitudes toward British and American culture, changed in the more positive direction).

Students' were not interested in CLIL-based math lessons to the extent we expected before. It seemed they had a neutral to mildly positive attitudes toward this kind of educational approach/methods. It will be interesting to explore students' and teachers' opinions and perceptions related to sociology, anthropology, philosophy, history, geography... classes taught in English (or some other well-known and frequently used foreign language, such as Spanish, German, or French).

In addition, we need more experimental studies on CLIL and non-CLIL environment in all levels of education (elementary, secondary, and tertiary one). If participants'attitudes, preferences, and achievements in the experimental group are better in a statistically significant manner (compared to the attitudes, preferences, and achievements of participants' in the control group), then we can indeed attribute them to the introduction of CLIL approach.

Of course, qualitative studies will reveal the true nature of students' and teachers' attitudes toward CLIL environment and their perceptions about pros and cons of such an approach in educational science and practice. We can also apply mixed method research design in order to examine the common patterns in CLIL-related topics and to investigate opinions and perceptions of CLIL pedagogy in-depth, that is, more thoroughly.

\section{References}

[1] Bobadilla-Perez, M. \& Galan-Rodriguez, N. M. (2015). CLIL materials in secondary education: Focusing on the language of instruction in the subject area of Mathematics. Revista de investigaciones y experiencias en Ciencias de la Educacion, 24, 32-49.

[2] Coyle, D. (1999). Theory and planning for effective classrooms: Supporting students in content and language integrated learning contexts. In Masih, J. (ed.), Learning through a foreign language. London: CILT.

[3] Coyle, D. (2005). Developing CLIL: Towards a theory of practice. APAC Monographs, 6, 5-29.

[4] Coyle, D. (2007). Content and language integrated learning: Towards a connected research agenda for CLIL pedagogies. International Journal of Bilingual Education and Bilingualism, 10, $5,543-562$.

[5] Coyle, D., Hood, P., \& Marsh, D. (2010). CLIL: Content and language integrated learning. Cambridge: CUP.

[6] De Lama, M. T. (2015). Making the match between content and foreign language: A case study on university students' opinions towards CLIL. Higher Learning Research Communications, 5, 1 , 29-46.

[7] Favilli, F., Maffei, L., \& Peroni, R. (2013). Teaching and learning mathematics in a non-native language: Introduction of the CLIL methodology in Italy. US-China Education Review, 3, 6, 374380 .

[8] Harrop, E. (2012). Content and language integrated learning (CLIL): Limitations and possibilities. Encuentro, 21, 57-70.

[9] King, M. (2018). Content and language integrated learning (CLIL). The TESOL Encyclopedia of English language teaching, 1-6. 
[10] Lasagabaster, D. \& Beloqui, R. L. (2015). The impact of type of approach (CLIL versus EFL) and methodology (book-based vaersus project work) on motivation. Porta Linguarum, 23, 41-57.

[11] Lasagabaster, D. \& Sierra, J. M. (2010). Immersion and CLIL in English: More differences than similarities. ELT Journal, 64, 4, 367-375.

[12] Marsh, D. (2002). CLIL/EMILE - The European dimension: Actions, trends and foresight potential. Strasbourg: European Commission.

[13] Papaja, K. (2012). The impact of students' attitude on CLIL: A study conducted in higher education. Latin American Journal of Content and Language Integrated Learning, 5, 2, 28-56.

[14] Prochazkova, L. T. (2013). Mathematics for language, language for mathematics. European Journal of Science and Mathematics Education, 1, 1, 23-28.

\section{Authors}

Azamat Akbarov, Kazakh National University, Almaty, Kazakhstan, azamatakbar@yahoo.com

Kemal Gonen, King Abdulaziz University, Jeddah, Saudia Arabia, kgonen@kau.edu.sa

Hakan Aydoğan, Independet researcher, Turkey, aydoganh@hotmail.com 


\section{Appendix}

\section{CLIL in math classes questionnaire}

1. Age:

2. Gender: Male / Female

3. What was your grade at the last math exam (please, provide a number)?:

4. What is the level of your English proficiency (choose the option that best fits your English proficiency)?
a) Elementary (A1)
b) Pre-intermediate (A2)
c) Intermediate (B1)
d) Upper intermediate (B2)
e) Advanced (C1)
f) Proficient (C2)

5. For how many years have you been learning English (please, enter a number)?

6. How much do you like your math classes taught in English (1 - not at all, 5 - very much)? $\begin{array}{lllll}1 & 2 & 3 & 4 & 5\end{array}$

7. What amount of effort do you put into participating in math classes taught in English? (1- very little effort, 5 - very great effort) $1 \quad 2 \quad 3 \quad 4 \quad 5$

8. What amount of effort do you put into doing homework (assignments) for math classes taught in English? (1- very little effort, 5 - very great effort) $1 \quad \begin{array}{lllll}1 & 2 & 3 & 4 & 5\end{array}$

9. What amount of effort do you put into preparing for math exams provided this school subject is taught in English? (1 - very little effort, 5 - very great effort) $1 \quad 2 \quad 3 \quad 4 \quad 5$

10. What is your level of satisfaction with math classes taught in English? (1 - very low, 5 - very high)? $1 \begin{array}{lllll}1 & 2 & 3 & 4 & 5\end{array}$

11. In which way did English-taught math courses changed your attitude toward British and American culture? ( 1 - to become very negative, 5 - to become very positive): $\begin{array}{lllll}1 & 2 & 3 & 4 & 5\end{array}$

12. How frequently do you have difficulties with understanding some math concepts taught in English? ( 1 - never, 2 - rarely, 3 - sometimes, 4 - often, 5 - almost always) $\begin{array}{lllll}1 & 2 & 3 & 4 & 5\end{array}$

13. To what extent did math classes taught in English improve your general English knowledge and communication skills? ( 1 - to a very small extent, 5 - to a very great extent) $\begin{array}{lllll}1 & 2 & 3 & 4 & 5\end{array}$

14. In general, do you like studying content subjects (chemistry, physics, biology...) in English? (1 $\begin{array}{llllll}\text { - not at all, } 5 \text { - very much) } & 1 & 2 & 3 & 4 & 5\end{array}$

15. Which one do you like more, math classes taught in English or in your mother tongue?
a) In English
b) In my mother tongue
c) I don't care because I like both languages of instruction equally

Thank you for your time and good luck with your further studies! 
